perature, and occasionally by a clearing of the intellect."

The oil of turpentine has served me, as it has many physicians who have written on typhoid fever, better than the ordinary astringents in checking this hrmorrhage.

\section{AGORAPHOBIA AGAIN.}

By S. G. Webner, M.D. Harv.

EXCEPT that a very able article on this subject has just been published in the Archiv f. Psychiatrie und Nervenkrankheiten, vol. iii. 3, containing an analysis of 29 cases, I should not have referred to this subject again.

Dr. Williams considers this symptom simply as a form of vertigo. Vertigo is "a state in which it seems that all objects are turning round ; or that the individual himself is performing a movement of gyration." Dunglieson. "The sensation of moving, or the appearance of moving objects without any real existence of movement." J. Spence Ramskill, in Reynolds's System of Medicine. So others might be quoted ; but in all the idea of circular motion is mentioned as a prominent characteristic. A person subject to vertigo might dread to cross a street alone, but why he should have a similar dread when sitting in a crowded theatre, is not so easily explained. However, there is no question of vertigo in these cases. Three patiente, whom I have seen since writing my last article, expressly deny that there is any sensation of dizziness or any swimming of the head. One of these could not cross a public square, was obliged to turn back and could not walk on the sidewalk next the square, but had to cross the street to the opposite side. Another, when at a concert or theatro felt oppressed or stifled, not from the close air of the room-for the same sensation was felt in a crowd in the streetbut a sense as of want of breath, and she thought she should faint if she gave way to the foeling; her. heart beat violently. The third patient was not dizzy except when she had a severe headache. She, however, had the sensations called agoraphobia on crossing a street or a square to to such a degree that she would be obliged to come to a stop and wait a few minutes before proceeding. She expressly said she was not dizzy at such times, and did not think of being dizzy.

I have seen patients in whom the vertiginous motion seemed to be around the longitudinal axis of the body; another in whom it was around an axis perpendicular to this axis, so that when upright, objects seemed to revolve over his head. Again, I have had a patient who complained of an undulatory sensation when walking, as though he were on board a ship. Another has complained that the ground seemed to riso to meet him as ho stepped, which may be the same as the last, differently described. I can understand how any of these sensations may be spoken of as a form of vertigo ; but when there is no sense as of motion, no swimming of the head, I do not see the propriety of using the word vertigo, or even the expression, "a form of vertigo."

Dr. Williams objects to the name of agoraphobia, and that, for consistency, appropriate classical terms ought to bo given to dread arising under other circumstances, as ecclesiaphobia. Inasmuch as arogx means not only a market-place, but also an assembly of people, the term agoraphobia would seem appropriate for the dread of crossing a square, or dread of being in a crowded room.

Dr. Williams has attempted to weaken the importance of the symptom we are considering, because it occur's in connection with other symptoms. If a person knows what vertigo is, he would be less likely to confound it and agoraphobia; because he has fits of an epileptic character, it does not follow that agoraphobia is epileptoid.

In each of the cases criticized, there were causes operating which might well produce the condition of irritable weakness or nervous erethism to which Dr. Cordes refers agoraphobia as a symptom, and it is not at all singular that other symptoms should be present referable to the same condition.

Dr. Williams does not describe the nature of the uneasiness to which he is subject under certain conditions accurately enough to render it certain whether he has ever experienced the sensation referred to as agoraphobia. In view of what he says, I can only suppose that he is not personally acquainted with it, and therefore has mistaken his sensations for it; it would also seem that he has not-met persons suffering from this symptom or has not carefully questioned them in regard to their sensations. Otherwise, I do not see how he should confound it with vertigo.

However, Dr. Cordes touches upon all the points which I wish to mention.

Dr E. Corcles prefers the name Platzangst to Agoraphobia. He says that some years ago, while greatly exhausted, he was him- 
self suddenly attacked with a feeling of very great mental fear while in a crowd of persons at the thoatre, against which the strongest effiort of the will was unable to contend successfully, and he was obliged to leave the theatre. He also subsequently had the sense of fear on crossing a wide place. Improvement followed on reöstablishment of the general health.

Plalzfurcht he is firmly persuaded should be looked upon not as a clearly specific disease, but it represents only a precise. species of certain psychical sensations of terror, of varying import, which are more or less similar, not differing in their quality, but only in their intensity, and all having the same cause; not that the notions and groups of ideas are always exactly the same-this would be psychologically impossible-but the train of ideas called forth is in the same circle of conceptions, united with nearly the same feeling of fear. The sense of terror in its lowest grade is shown only in the idea of fear lest some undefined evil should occur, the account of which differs according to the sensations of the patient, but is rather subacute. This lowest variety of fear increases partly intellectually, partly corporeally, while the one gives rise to ideas of terror, as also the other excites a sensation, not mental but bodily, until the whole mind is thrown into such anguish by this undefined something, this threatening terror, that strong reflex influence is excrcised over the motor facultics. Excessive palpitation is added thereto; an indescribable præcordial anxiety, oppression of the chest, efforts for breath, sensations of heat, alternating with cold and shivering, variations of temperature are present. A multitude of abnormal sensations run through the body and naturally increase the anguish still more; these sensations are especially like syncope; sense of diminishing power, as well bodily as mental. Soon pains darting through the head, dimness or glimmering before the eyes, sounds in the cars, nausea, a feeling like an aura rising from the stomach, weakness in the limbs or in groups of muscles in other parts of the body, formication, sense of Hlushing, \&c., are mingled confusedly together, and excite the most indefinite succession of ideas, which end and culminate in the sense of indescribable anguish.

In the lower degrees of this sense of agony the will can overcome it; as it becomes more severe, however, it overpowers the will and the body dominates the soul. In this condition every impression upon the nerves of sense excites powerful reflex conditions. He considers the platzangst as only one variety of this sensation of psychical anguish, which arises nearly always in the same way.

The feelings and sensations which the patient experiences during or before crossing a large square are never analogous to vertigo; never is there a feeling as if the patient or surrounding objects turned round; never is there apparent motion, but always he feels a sense of powerlessness, as if he could not go forwards, as if chained to the ground, and from this arises the fear of inability to cross the place. This anxiety increases sometimes to such a pitch that genuine reflex paresis results, and there is momentary inability to perform coördinated motions of the legs. If the pationt can control himself sufficiently to go slowly and retard his motions, instead of trying to overcome the paresis by rapid walking, he sees that he has not lost power over his limbs, that the anxiety was unnecessary, and he becomes quiet and can then cross the square.

Agoraphobia is caused by associations of ideas derived externally ; it is not a disease by itself, but only a symptom, whose basis, in common with that of other similar symptorns, we must seek. At the foundation of these sensations of anxiety lies one common, or at least similar, corporeal cause. They occur in a certain pathological group, including what may be expressed by the name nervous irritability, crethism, irritable weakness. As yet this is a very unprecise term; by it may be understood an increased impressionability for irritations, as well of the peripheral sensitive nervous system as of the organs of sense, which are so reflected upon the central nervous system that not only the psychical but also the entire nervous system, the motor, vaso-motur and trophic may be thrown into extreme commotion, follow. ed often, not always, by great exhaustion. The causes which call forth this changed centripetal and centrifugal nervous conduction, may vary; whether the anatomical basis varies equally is as yet unknown to us, and will remain unknown until we have more data. Yet each step which we take in the more correct grouping and classification of single symptoms belunging to nervous weakness marks an advance which brings us nearer a knowledge of the anatomical basis.

Cordes gives the histories of three par tients as examples of the three groups :1st, where tho anxiety is felt in the presence of large numbers of people; $2 \mathrm{~d}$, when alone; $3 \mathrm{~d}$, agoraphobia proper.

IIe finds that all the 29 patients suffered 
from a, so-called, irritable weakness ; that they all, under cortain conditions, had a sense of anxiety or terror ; that the causes through which the nervous erethism arose may be referred to a few, chicfly three, divisions :-1st, mental over-exertion:; $2 \mathrm{~d}$, dissolute life; $3 \mathrm{~d}$, chronic gastric disturbance.

The same symptoms will not invariably follow every cause of debility. There seems to be one symptom which forms the characteristic difference between exhaustion caused by dissipation, mental over-exertion and gastric disturbance, and the exhaustion arising from other causes. This symptom is tremor, from which all the patients under consideration suffered.

Tremor must be considered as an excess of muscular action which easily passes into a deficiency of muscular action. It may arise from over-irritation of peripheral nerve-endings, in the reflex centres or in deficient action of the will. In all the patients whose cases are included in the table, and whose affection depended upon the three causes above mentioned, the tremor depended upon defective impulse of the will. This tremor is not like that which is seen after typhus or after extreme bodily exertion. These patients can take long walks without being tired, can stand for hours without trembling, can work half the night and lie without sleep the other half, and the next morning show no sign of trem. bling. So soon, however, as certain groups of ideas seize their minds, a severe tremor appears, against which every resistance is powerless, which, with the invariably accompanying fear may even cause paresis.

It seems to be characteristic of this action of certain exhausting irritations that the control of the will over the motor cen. tres is disturbed. It would seern also that in such cases there is a pathological change, as yet unknown, in that part of the brain which is concerned not only with locomotion, but also with general muscular sensibility, so modifying the mind that after the sensation of fright, a tremor may arise and, in the highest degree, a paresis of the muscles. This sensation of mental terror is never found with the tremor after typhus.

Agoraphobia is a variety of functional paralysis which, neither in its import nor in its grouping of symptoms, nor in its effects, is anything else than a certain degree of intensity of the mental terror before referred to.

One patient represented that secing a large crowd on the ice he became suddenly dizzy. On more careful questioning, it was found that there was no dizziness, no semblance of motion in surrounding objects or in himself; but on account of a succession of sensations resembling faintness, dimness and glimmering before his eyes, instability of the legs, \&c., he was overpowered by the thought that it would be impossible to pass over the smooth ice and among so many persons.

The sense of terror here described differs essentially from the stomachal vertigo described by Trousseau. An important diagnostic mark is that this sense of terror arises from the same circumstances, in a wide place, in the midst of a crowd, as when alone; it may also be voluntarily excited, which is not the case in stomachal vertigo.

In all the cases the eyesight was intact; in none was there an epileptoid condition or true epilepsy. 'True paralysis or paralytic symptoms did not appear apart from the condition of terror. In most casesall except four-the nutrition was good, the muscles being compact and firm, exertion did not cause weariness. Men were chiefly affected; one woman only had the disease, and she had also Basedow's discase; the patients were in the vigor of life, and from the better classes. It was not uncommon for the patients to fear lest they should become insane, or should die suddenly. All, however, recovered.

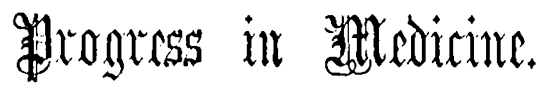

\section{REPORT ON SURGERY.}

By J. Colisins Wamur, M.D., Boston.

(Concluded from page 434.)

Ovarian Tumors: their Pathology, Diarnosia and 'T'rentment, especinlly by Orariotomy. By E. Randolph Peaslee, M.D., LL.D.

In the chapter on the classification and pathological anatomy of ovarian tumors, we find the following varieties mentioned:

I. Solid ovarian tumors consisting of, 1 , Enchondroma ; 2, Osteoma; 3, Carcinoma ; 4, Papilloma; 5, Fibroma of tho Corpora Lirtea or of the Stroma.

Carcinoma of the ovary is placed among the rare forms. The encephaloid form is said to be the most common, but it is considered by the author to be less so than scirrhus. Cancer is said usually to affect both ovaries. Spencer Wells has seen but three cases in his first four hundred cases of ovariotomy, and the author has seen but two undoubted and two strongly suspected 